\title{
Biosynthesis of Silver Nanoparticles Using Pine Pollen and Evaluation of the Antifungal Efficiency
}

\author{
Mehrdad Khatami ${ }^{1-4^{*}}$, Seyed Mojtaba Mortazavi ${ }^{1}$, Zeinab Kishani-Farahani ${ }^{5}$, Abbas Amini ${ }^{6}$, Elham \\ Amini ${ }^{3}$, Hossein Heli ${ }^{4 *}$ \\ ${ }^{1}$ School of Medicine, Bam University of Medical Sciences, Bam, Iran. \\ ${ }^{2}$ Leishmaniasis Research Center, Kerman University of Medical Sciences, Kerman, Iran \\ ${ }^{3}$ Research Center for Tropical and Infectious Diseases, Kerman University of Medical Sciences, Kerman, Iran \\ ${ }^{4}$ Nanomedicine and Nanobiology Research Center, Shiraz University of Medical Sciences, Shiraz, Iran \\ ${ }^{5}$ Research and Development Center, Taleghani Hospital, Shahid Beheshti University of Medical Sciences, Tehran, Iran \\ ${ }^{6}$ Institute for Infrastructure Engineering, Western Sydney University, Kingswood Campus, Locked Bag 1797, NSW 2751, Australia
}

\begin{abstract}
${ }^{*}$ Corresponding authors: Hossein Heli, Nanomedicine and Nanobiology Research Center, Shiraz University of Medical Sciences, Shiraz, Iran. E-mail: hheli7@yahoo.com, heli@sums.ac.ir, Tel: +98 71 36122225,6; Fax: +98 71 36281506, and Mehrdad Khatami, School of Medicine, Bam University of Medical Sciences, Bam, Iran. E-mail: m.khatami@mubam.ac.ir, Tel/fax: +98 34344219074
\end{abstract}

Received: 5 Jan. 2016;

Revised:7 Jan. 2017;

Accepted: 19 June 2017;

Published online: 19 August 2017

Background: Nanoparticles have been applied to medicine, hygiene, pharmacy and dentistry, and will bring significant advances in the prevention, diagnosis, drug delivery and treatment of disease. Green synthesis of metal nanoparticles has a very important role in nanobiotechnology, allowing production of non-toxic and eco-friendly particles.

Objectives: Green synthesis of silver nanoparticles (AgNPs) was studied using pine pollen as a novel, cost-effective, simple and non-hazardous bioresource. The antifungal activity of the synthesized AgNPs was investigated in vitro.

Materials and Methods: Biosynthesis of AgNPs was conducted using pollen of pine (as a novel bioresource) acting as both reducing and capping agents. AgNPs were characterized using UV-visible spectroscopy, X-ray diffraction and transmission electron microscopy. In evaluation for antifungal properties, the synthesized AgNPs represented significant in vitro inhibitory effects on Neofusicoccum parvum cultures.

Results: Pine pollen can mediate biosynthesis of colloidal AgNPs with an average size of $12 \mathrm{~nm}$. AgNPs were formed at $22^{\circ} \mathrm{C}$ and observed to be highly stable up to three months without precipitation or decreased antifungal property. AgNPs showed significant inhibitory effects against Neofusicoccum parvum.

Conclusion: The first report for a low-cost, simple, well feasible and eco-friendly procedure for biosynthesis of AgNPs was presented. The synthesized AgNPs by pine pollen were nontoxic and eco-friendly, and can be employed for large-scale production. The nanoparticles showed strong effect on quantitative inhibition and disruption of antifungal growth.

Keywords: Colloidal silver, Green synthesis, Low-cost synthesis, Pollen.

\section{Background}

Nanotechnology has attracted attentions in many researchers worldwide (1-4). Nanoparticles have gained increased use due to their specific performance in pharmacy, medicine and engineering (5-8). Silver nanoparticles (AgNPs) with strong antibacterial activity have been commercialized to control wide spectrum of bacteria (9-11). Some AgNPs-based products are being used in shampoos, soaps, detergents, toothpastes, cosmetics-hygienic and medicinal goods (12); even though not all such products have been proven safe and gained approval by United States
Environmental Protection Agency (EPA) yet. AgNPs are being synthesized by various physical and chemical techniques $(13,14)$ including electrochemical $(15)$ and photochemical (13). These techniques are generally expensive, time consuming, difficult to manage, and leave toxic chemicals. To avoid such hazardous effects, biosynthesized nanoparticles by microorganisms, plant extracts or enzymes have gained attentions (16-19). For instance, Cassia auriculata L. (20), fennel (10) or other plant extracts $(21-24)$, fungi $(25,26)$, and bacteria $(27,28)$ were used to synthesize AgNPs and some other metal nanoparticles. These nanoparticles have 


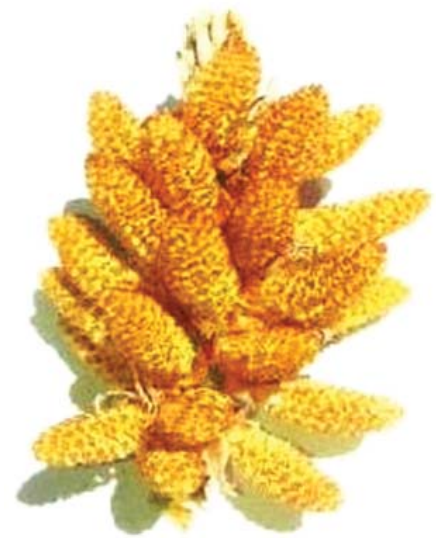

Figure 1. Male cones of pine tree used to collect pollens.

demonstrated antibacterial activities against a wide array of gram positive and negative bacteria (10).

Here, pine pollen (Fig. 1) for the first time was used to biosynthesis AgNPs.

\section{Objectives}

The main goal of the present study was to evaluate biosynthesis of antifungal metalic nanoparticles using green route. Green synthesis of AgNPs were studied and characterized using pine pollen as a novel, cost-effective, simple and non-hazardous bioresource. The antifungal effect of the resulting green synthesized AgNPs was investigated in vitro on Neofusicoccum parvum.

\section{Materials and Methods}

\subsection{Materials}

The male cones were collected from pine tree in spring of 2015, in Kerman University of Medical Sciences. $\mathrm{AgNO}_{3}$ and potato dextrose agar (PDA) medium were purchased from Merck, Germany. The fungal isolate $N$. parvum was obtained from Shahid Bahonar University of Kerman bio-bank, Kerman, Iran.

\subsection{Preparation of Pollen Water-Extract (PWE)}

The male cones of pine were collected and surface sterilized using $2 \%(\mathrm{v} / \mathrm{v})$ sodium hypochlorite for 3 min, followed by 3 min rinsing with deionized water (DW). Disinfested male cones macerated in DW (1 g.20 $\mathrm{mL}^{-1} \mathrm{DW}$ ), and incubated at $28^{\circ} \mathrm{C}$ for $48 \mathrm{~h}$ in dark (21). Male cones were removed from the maceration mixture and the aqueous phase was collected and centrifuged at $1.4 \times 103 \times g$ for $10 \mathrm{~min}$ to separate the liquid fraction from the pollen particles. The pellets were discarded and the supernatant was filtered through Whatman filter paper No.42. The cell free extract was stored at $4{ }^{\circ} \mathrm{C}$.

\subsection{Biosynthesis of AgNPs}

To evaluate the reduction of silver ions to $\mathrm{Ag}$, cellfree PWE was two-fold diluted by sterile DW and its aliquots were mixed with equal volumes of several concentrations of $\mathrm{AgNO}_{3}(1,2.5,4.0$ and $5.0 \mathrm{mM})$.A control sample was received water with no $\mathrm{AgNO}_{3}$. All the procedures were repeated in triplicates. The samples were stored at $28^{\circ} \mathrm{C}$ in dark for $16 \mathrm{~h}$.

\subsection{UV-visible Spectroscopy Analysis}

The formation of AgNPs was monitored by UV-visible spectroscopy in Scan drop-type spectrometer (Analytik Jena, Germany). Absorption values were recorded in a wavelength of 300-650 $\mathrm{nm}$.

\subsection{Stability of AgNPs}

The synthesised AgNPs were kept stationary over 3 months in dark for all concentrations and evaluated visually every week for probable colloid, aggregate or precipitate formation.

\subsection{X-ray Diffraction (XRD) Analysis}

To prepare a powder sample, $60 \mathrm{~mL}$ PWE containing synthesized AgNPs was centrifuged for $8 \mathrm{~min}$ at $1.19 \times 104 \times g$, the supernatant was discarded, and 60 $\mathrm{mL}$ DW was added to the pellets. This procedure was repeated in two additional cycles and the remaining pellets were dried at $60{ }^{\circ} \mathrm{C}$ for $48 \mathrm{~h}$. The resultant powder was used for XRD analysis. An X-ray of 1.54 $\AA$ wavelength over a angel range of 10 to $80^{\circ}$ was employed (29). The most widely used method for estimating the average crystallite size of AgNPs is based on the full width at half maximum (FWHM) of a diffraction peak using the Scherrer equation:

$\mathrm{D}=\mathrm{k} \lambda / \beta_{1 / 2} \cos \theta$

where $\mathrm{D}, \lambda, \mathrm{k}, \beta_{1 / 2}, \theta$, are the crystal size, X-ray wavelength, the Scherer coefficient, FWHM, and Bragg angle, respectively.

\subsection{Transmission Electron Microscopy (TEM)}

TEM images of the synthesized AgNPs were recorded using a CARL ZEISS transmission electron microscope working at $80 \mathrm{kV}$.

\subsection{Bioassays of Antifungal Activity of AgNPs}

To determine the antifungal activity of the synthesized AgNPs, agar diffusion method was employed, and the zones of inhibition were measured (5). AgNPs of different concentrations were mixed with PDA growth medium $\left(5,10,15\right.$ and $\left.30 \mu \mathrm{g} \cdot \mathrm{mL}^{-1}\right)$ after autoclaving 
and prior to pouring in Petri plates $(75 \times 15 \mathrm{~mm})$. After solidification, each Petri plate was inoculated with a 6 $\mathrm{mm}$ agar plug of 7 days old culture of $N$. parvum at the center and incubated at $28 \pm 1{ }^{\circ} \mathrm{C}$. Controls included PDA medium with no AgNPs and inoculated similarly. When the fungus on control plates relatively covered the entire surface of the medium (4 days), the mean radius of fungal growth in all treatments were recorded (30). The experiments were performed in triplicates and mean values were recorded. To evaluate the antifungal activity, the following formula was used to assess the rate of fungal inhibition:

$\%$ Inhibition rate $=(\mathrm{R}-\mathrm{r}) / \mathrm{R}$

where $\mathrm{R}$ is the radius of mycelia growth of control and $r$ indicates radius of fungal growth mycelia in treated samples containing AgNPs. Data was subjected to analysis of variance (ANOVA) with SAS Software (SAS Institute, version 9, Cary, NC). Statistical significance was determined at the $\mathrm{p} \leq 0.01$. Duncan's Multiple-Range Test was used to compare the means.

\section{Results}

\subsection{Visual Observation}

Upon addition of PWE to $\mathrm{AgNO}_{3}$ solution, reduction of the silver ions to Ag occurred, and the reduction reaction was noticeable in mixtures through color change from colorless to reddish brown (Fig. 2). This reddish brown color is attributed to the Surface Plasmon Resonance (SPR) arising due to the collective oscillation of induced free conduction electrons in AgNPs (31).

\subsection{UV-Visible Spectrophotometry}

Figure 3 shows UV-visible spectra for PWE, and after mixing with 1, 2.5, 4.0 and 5.0 $\mathrm{mM} \mathrm{AgNO}_{3}$. The AgNPs solutions represented a maximum optical absorption at

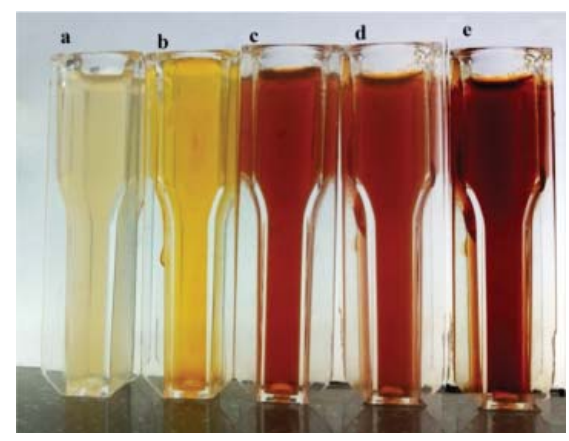

Figure 2. Color changes of PWE upon mixing with $\mathrm{AgNO}_{3}$. a) PWE, b) PWE plus 1.0, c) plus 2.5, d) plus 4.0, and e) plus $5.0 \mathrm{mM} \mathrm{AgNO}_{3}$.

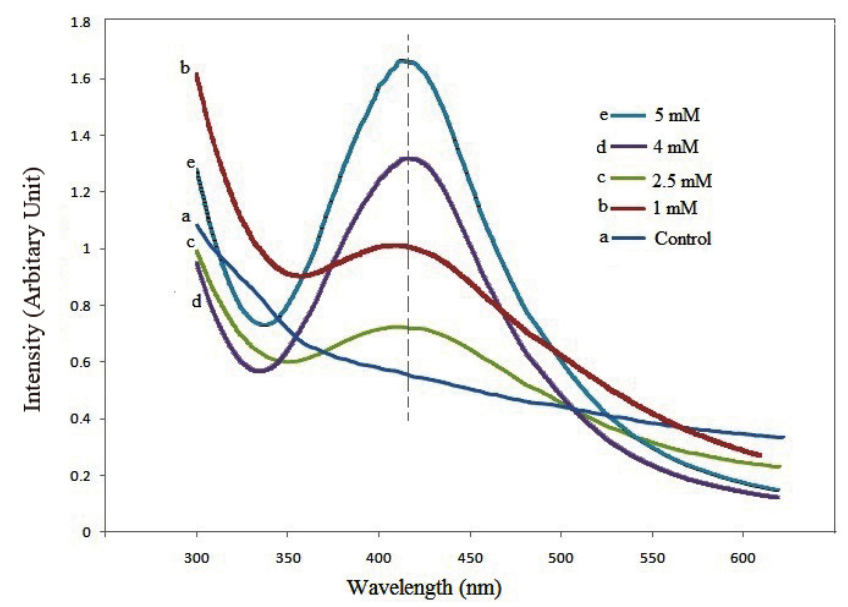

Figure 3. UV-visible absorption spectra of PWE, and after mixing with 1, 2.5, 4.0 and $5.0 \mathrm{mM} \mathrm{AgNO}_{3}$

$\approx 414 \mathrm{~nm}$, and the related absorbance was increased upon AgNPs concentration increment.

\subsection{Stability of AgNPS}

The synthesised AgNPs represented a colloidal stability in long time at ambient temperature. It was observerd that AgNPs synthesized with $1 \mathrm{mM} \mathrm{AgNO}_{3}$ were stable for 5 months, and those with 2.5, 4.0 and $5.0 \mathrm{mM}$ were stable for 2, 1 and 1 months, respectively.

\subsection{XRD Analysis}

An XRD pattern recorded for the synthesized AgNPs is presented in Figure 4. The pattern contained prominent peaks at $2 \theta$ values of $38,44,64$ and $77^{\circ}$, corresponding to (1 11 1), (2 00 0), (2 200$)$ and (3 11 1) planes, respectively. The pattern corresponds to crystalline phase of FCC structure. It should also be added that the other peaks (at $2 \theta$ values of $32,54,57$ and $67^{\circ}$ ) in the pattern are due to the crystallization of bioorganic phase on the surface of the nanoparticles (32). Similar results were reported elsewhere (33). The average crystalline size of AgNPs was obtained as $20 \mathrm{~nm}$.

\subsection{TEM Analysis}

TEM images of the synthesized AgNPs at two magnifications are presented in Figure 5, and a particle size distribution histogram is shown in Figure 6. AgNPs had a spherical shape with ultra small size with an average size of $12 \mathrm{~nm}$.

\subsection{Antifungal Activity of AgNPS}

In vitro bioassays of fungi-static properties of AgNPs were revealed by inhibition of mycelia growth of Neofusicoccum parvum on PDA growth medium amended with AgNPs. The antifungal activity of 


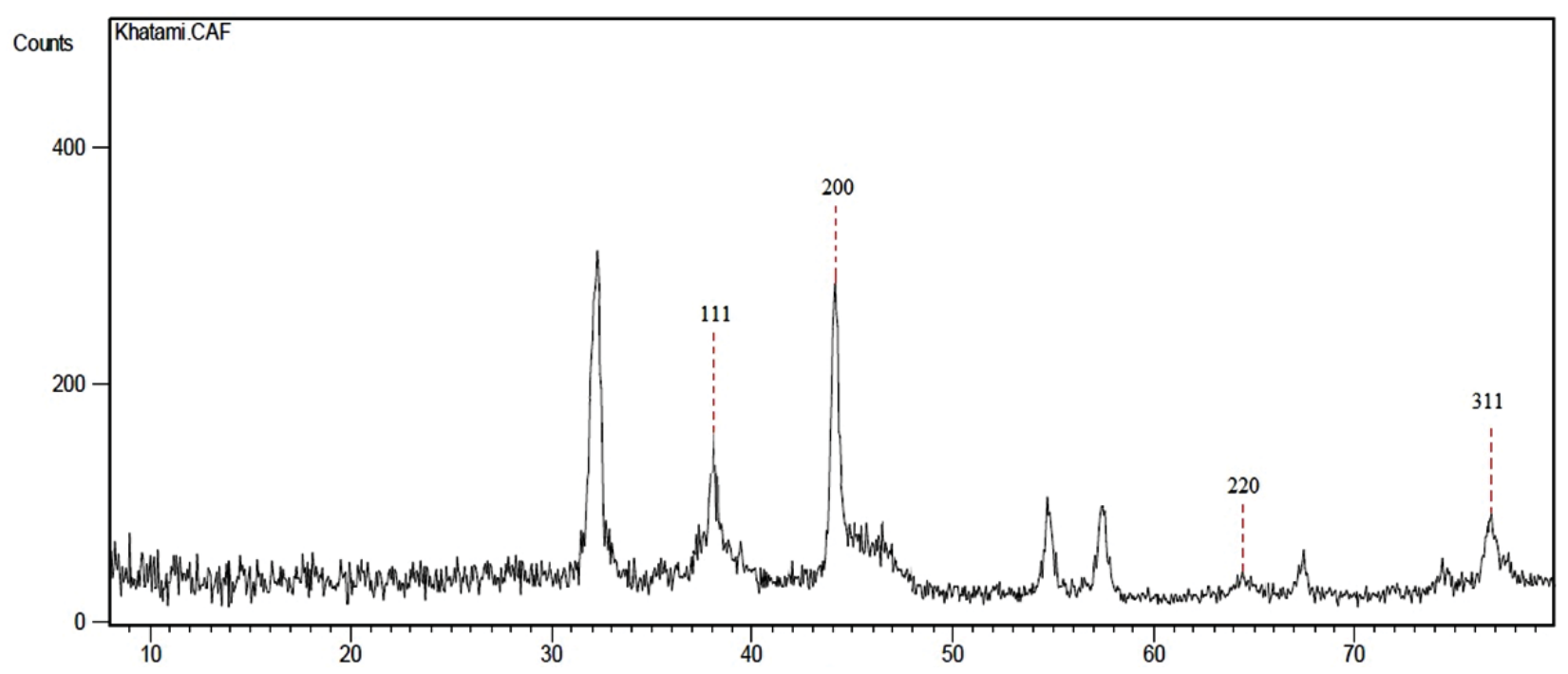

Figure 4. An XRD pattern of the synthesized AgNPs.

AgNPs for the concentrations of 5.0, 10, 15, and $30 \mathrm{ppm}$ was found to be concentration dependent. Images form he bioassay plates are shown in Figure 7. The inhibition percents were obtained as 41,58 , 68 and $81 \%$ for the concentrations of 5.0, 10, 15 and $30 \mathrm{ppm}$, respectively. The data was subjected to the analysis of variance (ANOVA) and Duncan's MultipleRange test was employed to compare the means of triplicate treatments. The results confirmed a significant inhibitory effect $(\mathrm{P}<0.01)$ of AgNPs on fungal growth at all tested concentrations.
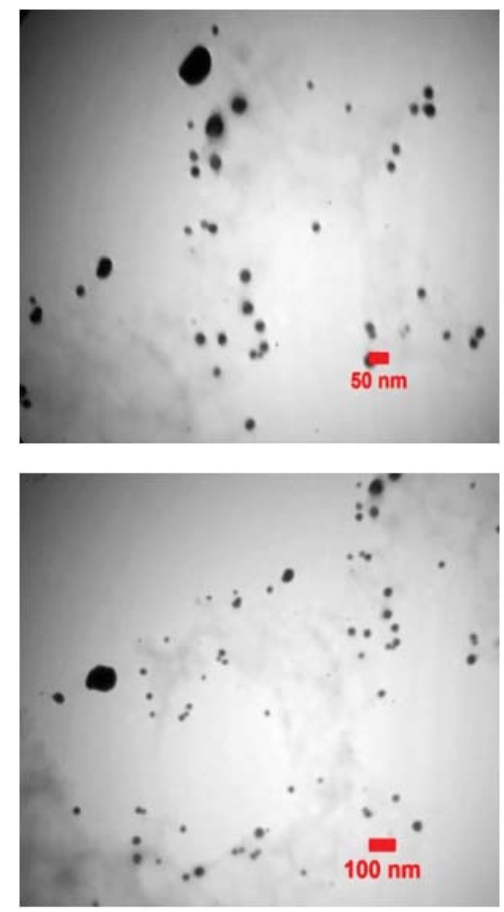

Figure 5.TEM images of the synthesized AgNPs.

\section{Discussion}

Kumarasamyraja and Swamivelmanickam biosynthesized spherical AgNPs with a size of 15-20 nm (20), Bonde et al. synthesized AgNPs in a diameter range of 18-83 $\mathrm{nm}$ (10), and Soltani Nejad et al. reported the biosynthesis of triangular AgNPs with a size range of 1-100 nm (34). Amaladhas and his coworkers showed that Cassia angustifolia nanoparticles were poly-dispersed with a particle size of 9-31 nm (an average size of $21.6 \mathrm{~nm}$ ) (35). Using banana, neem and tulsi for the synthesis of AgNPs resulted in spherical, triangular and cuboidal AgNPs, respectively (33). Her, this is the first report on rapid, simple and non-hazardous method for the synthesis of very small-sized AgNPs from PWE and their strong effect on quantitative inhibition of fungal mycelium growth. PWE was efficiently and successfully used for one-step biosynthesis of

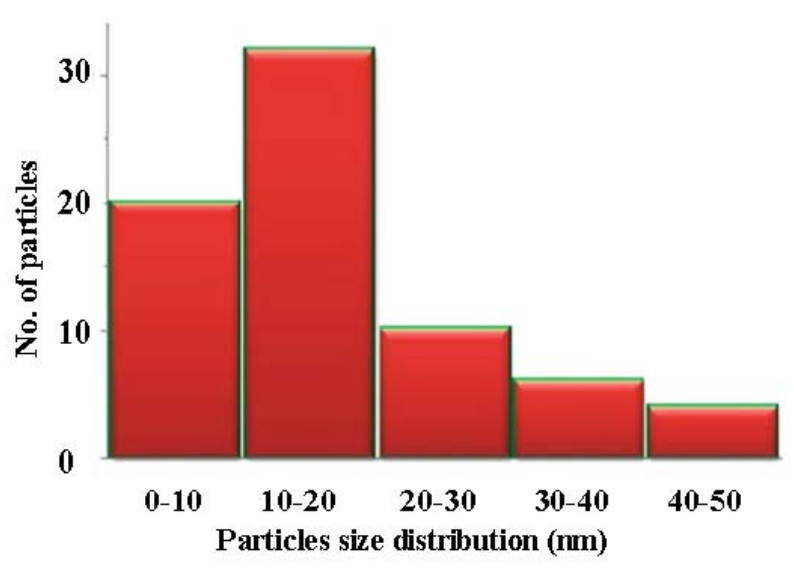

Figure 6. A particle size distribution of the synthesized AgNPs. 


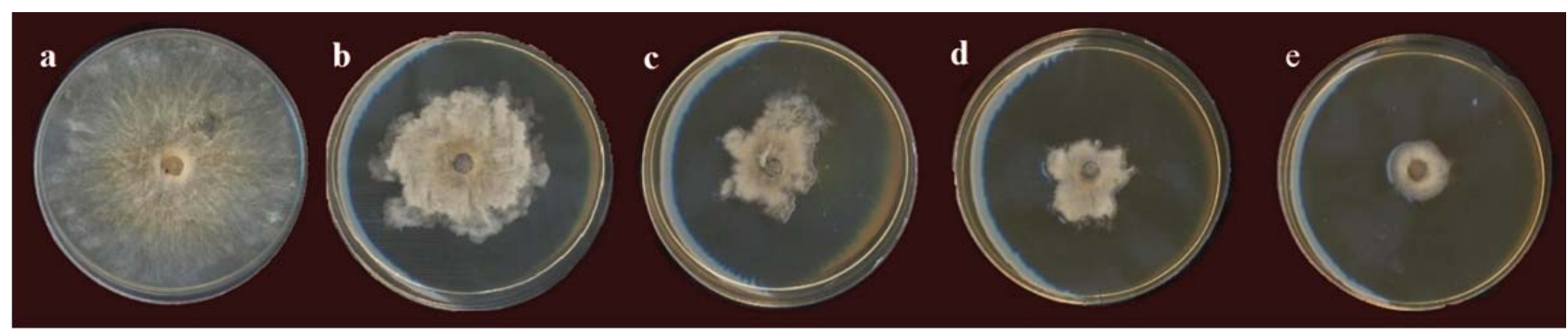

Figure 7: Fungi-static properties of AgNPs at concentrations of a) 0 (control), b) 5.0, c) 10, d) 15, and e) $30 \mathrm{ppm}$.

spherical AgNPs in ambient conditions in $10 \mathrm{~min}$. Stability of AgNPs was significantly dependent on the concentration; they were more stable at lower concentrations. PWE simultaneously played both the reducing and stabilizing actions, and prevented the nanoparticles aggregation. The synthesis reaction did not require any chemical, solvent or high energy consumption. The methodology promises a rather easy scale-up procedure for production of AgNPs.

The differences in size, charge, stability, shape, and morphology of AgNPs can be characterized by UVvisible spectra. The peak in UV-visible spectra of the synthesized AgNPs had a maximum at $414 \mathrm{~nm}$ similar to that reported for AgNPs synthesized by Butea monosperma (36), while, had a blue shift compared to that measured for AgNPs synthesized by Cycas leaf (37). The difference is due to the size and shape of the AgNPs.

The antifungal and antibacterial activities of silver nanostructures have already been known $(7,16,35$, 3841). In the present study, the inhibitory effect of AgNPs was assayed against Neofusicoccum parvum. AgNPs can represent this inhibitory effect through different mechanisms including i) binding to cytoplasmic membrane causing cell membrane damage, forming pits on the cell surface, and/or modifying cell wall permeability, ii) inhibition of major cellular functions such as respiration, DNA replication, and cell division, resulting in loss of cell viability $(38,42)$. It should be also added that this inhibitory effect is size-dependent enhancing with decrement in the size (42-44).

\section{Conclusion}

It was shown that pine pollen extract is a suitable reducing and stabilizing agent. The extract can be applied for the synthesis of other noble metal nanostructures. The proposed procedure for the synthesis of AgNPs can be applied for the large-scale production for antimicrobial sprays, cosmetic creams etc, although more investigations are needed to understand the toxicity and mechanism of action at cellular level.

\section{Acknowledgements}

We would like to thank Bam University of Medical Sciences and the Research Council of Shiraz University of Medical Sciences (13155) for supporting this research.

\section{Authors' Contribution}

All authors have participated in the manuscript preparation.

\section{Financial Disclosure}

There is no conflict of interest.

\section{Funding/Support}

The study was supported by Bam University of Medical Sciences and Shiraz University of Medical Sciences.

\section{References}

1. Shakibaie M, Forootanfar H, Golkari Y, Mohammadi-Khorsand T, Shakibaie MR. Anti-biofilm activity of biogenic selenium nanoparticles and selenium dioxide against clinical isolates of Staphylococcus aureus, Pseudomonas aeruginosa, and Proteus mirabilis. J Trace Elem Med Bio. 2015; 29:235-41. DOI: 10.1016/j.jtemb.2014.07.020.

2. Moghaddam HM, Beitollahi H, Tajik S, Jahani S, Khabazzadeh $\mathrm{H}$, Alizadeh R. Voltammetric determination of droxidopa in the presence of carbidopa using a nanostructured base electrochemical sensor. Rus J Electrochem. 2017; 53(5):452460. DOI: $10.1134 / \mathrm{S} 1023193517050123$.

3. Beitollahi H, Tajik S, Jahani S. Electrocatalytic Determination of Hydrazine and Phenol Using a Carbon Paste Electrode Modified with Ionic Liquids and Magnetic Core-shell Fe3O4@ SiO2/MWCNT. Nanocom Electro 2016; 28(5):1093-1099. DOI: 10.1002/elan.201501020.

4. Abedi G, Sotoudeh A, Soleymani M, Shafi ee A, Mortazavi P, Afl atoonian MR. A collagen-poly (Vinyl Alcohol) nanofi ber scaff old for cartilage repair. J Biomater Sci Polym Ed. 2011; 22(18):2445-55. DOI: 10.1163/092050610X540503.

5. Khatami M, Heli H, Jahani P.M, Azizi H, Lima Nobre M. Copper/copper oxide nanoparticles synthesis using Stachys lavandulifolia and its antibacterial activity. IET Nanobiotech. 2017; 11. DOI: 10.1049/iet-nbt.2016.0189.

6. Miri A, Sarani M, Bazaz MR, Darroudi M. Plant-mediated biosynthesis of silver nanoparticles using Prosopis farcta 
extract and its antibacterial properties. Spectrochi Act Part A: Mol and Biomol Spect. 2015; 141(5):287-291. DOI: 10.1016/j. saa.2015.01.024.

7. Miri A, Dorani N, Darroudi M, Sarani M. Green synthesis of silver nanoparticles using Salvadora persica L. and its antibacterial activity. Cell Mol Bio. 2016; 62(9): 46-50. DOI: 10.14715/cmb/2016.62.9.8.

8. Hamedi S, Shojaosadati SA, Shokrollahzadeh S, HashemiNajafabadi S: Mechanism study of silver nanoparticle production using Neurospora intermedia. In: IET Nanobiotech. 2017; 11:157-163. DOI: 10.1049/iet-nbt.2016.0038.

9. Hamedi S, Shojaosadati SA, Mohammadi A: Evaluation of the catalytic, antibacterial and anti-biofilm activities of the Convolvulus arvensis extract functionalized silver nanoparticles. J Photochem Photobio B: Bio. 2017; 167:36-44. DOI: 10.1016/j.jphotobiol.2016.12.025.

10. Alishah H, Pourseyedi S, Ebrahimipour SY, Mahani SE, Rafiei $\mathrm{N}$ : Green synthesis of starch-mediated $\mathrm{CuO}$ nanoparticles: preparation, characterization, antimicrobial activities and in vitro MTT assay against MCF-7 cell line. Rend Fis Acc Lincei. 2017; 28(1):65-71. DOI: 10.1007/s12210-016-0574-y.

11. Mahmoudvand H, Shakibaie M, Tavakoli R, Jahanbakhsh S, sharifi I. In Vitro Study of Leishmanicidal Activity of Biogenic Selenium Nanoparticles against Iranian Isolate of Sensitive and Glucantime-Resistant Leishmania tropica. Iran J Parasito. 2014; 9(4):452-460. DOI: 10.1049/i-para.2014.004.

12. Bansod SD, Bawaskar MS, Gade AK, Rai MK. Development of shampoo, soap and ointment formulated by green synthesised silver nanoparticles functionalised with antimicrobial plants oils in veterinary dermatology: treatment and prevention strategies. IET Nanobiotech. 2015; 9(4): 165-71. DOI: 10.1049/ iet-nbt.2014.0042.

13. Gabriel JS, Gonzaga VAM, Poli AL, Schmitt CC. Photochemical synthesis of silver nanoparticles on chitosans/montmorillonite nanocomposite films and antibacterial activity. Carbo Poly. 2017; 171:202-210. DOI: 10.1016/j.carbpol.2017.05.021.

14. Qin Y, Ji X, Jing J, Liu H, Wu H, Yang W. Size control over spherical silver nanoparticles by ascorbic acid reduction. Coll Surf A: Physicoc Eng Asp. 2010; 372(3):172-6. DOI: 10.1016/j. colsurfa.2010.10.013.

15. Nasretdinova GR, Fazleeva RR, Mukhitova RK, Nizameev IR, Kadirov MK, Ziganshina AY, Yanilkin VV. Electrochemical synthesis of silver nanoparticles in solution. Electrochem Comm. 2015: 50:69-72. DOI: 10.1016/j.elecom.2014.11.016.

16. Ahmed S, Ahmad M, Swami BL, Ikram S. A review on plants extract mediated synthesis of silver nanoparticles for antimicrobial applications: A green expertise. J Adv Res. 2016; 7(1):17-28. DIO:10.1016/j.jare.2015.02.007.

17. Hamedi S, Ghaseminezhad M, Shokrollahzadeh S, Shojaosadati SA.Controlled biosynthesis of silver nanoparticles using nitrate reductase enzyme induction of filamentous fungus and their antibacterial evaluation. Art Cell Nanomed Biotech. 2016:1-9. DOI: 10.1080/21691401.2016.1267011.

18. Zare E, Pourseyedi S, Khatami M, Darezereshki E. Simple biosynthesis of zinc oxide nanoparticles using nature's source, and it's in vitro bio-activity. J Mol Stru. 2017;1146: 96-103. DOI: 10.1016/j.molstruc.2017.05.118.

19. Darroudi M, Sarani M, Kazemi Oskuee R, Khorsand Zak A, Amiri MS. Nanoceria: Gum mediated synthesis and in vitro viability assay. Cera Int. 2014; 40(2): 2863-2868. DIO: .org/10.1016/j.ceramint.2013.10.026.
20. Kumarasamyraja D, Swamivelmanickam M. Evaluation Of Wound Healing Activity Of Biosynthesized Silver Nanoparticles From Aqueous Extract Of Cassia Auriculata L. Int J Phytopharm. 2014; 5: 201-9. DIO: 10.1016/j..2014.10.

21. Khatami M, Mehnipor R, Sobhani Poor MH, Salehi Jouzani GH. Facile Biosynthesis of Silver Nanoparticles Using Descurainia sophia and Evaluation of Their Antibacterial and Antifungal Properties. J Clus Sci. 2016; 27(5): 1601-1612. DOI: 10.1007/ s10876-016-1028-5.

22. Azizi Z, Pourseyedi $\mathrm{Sh}_{2}$ Khatami M, Mohammadi H. Stachys lavandulifolia and Lathyrus sp. mediated for Green Synthesis of Silver Nanoparticles and Evaluation Its Antifungal Activity Against Dothiorella sarmentorum. J Clus Sci. 2016; 27(5): 1613-1628. DOI: 10.1007/s10876-016-1024-9.

23. Vijayakumar M, Priya K, Nancy FT, Noorlidah A, Ahmed ABA. Biosynthesis, characterisation and anti-bacterial effect of plantmediated silver nanoparticles using Artemisia nilagirica. Ind Cro Produ. 2013; 41:235-40. DOI: 10.1016/j.indcrop.2012.04.017.

24. Moon SA, Salunke BK, Alkotaini B, Sathiyamoorthi E, Kim BS. Biological synthesis of manganese dioxide nanoparticles by Kalopanax pictus plant extract. IET Nanobiotech. 2015; 9(4): 220-225. DOI: 10.1049/iet-nbt.2014.0051.

25. Kelkawi AHA, Kajani AA, Bordbar A-K. Green synthesis of silver nanoparticles using Mentha pulegium and investigation of their antibacterial, antifungal and anticancer activity. In: IET Nanobiotech. 2017; 11(4): 2017: 370-376. DOI: 10.1049/ietnbt.2016.0103.

26. Oves M, Qari HA, Felemban NM, Khan MZ, Rehan ZA, Ismail IMI. Marinobacter lipolyticus from Red Sea for lipase production and modulation of silver nanomaterials for anticandidal activities. IET Nanobiotech. 2017; 11: 403-410. DOI: 10.1049/iet-nbt.2016.0104.

27. Mortazavi SM, Khatami M, Sarifi I, Heli H, Kaykavousi K, Sobhani MH, Kharazi S, Nobre ML. Bacterial biosynthesis of gold nanoparticles using Salmonella enterica subsp. enterica serovar Typhi isolated from blood and stool specimens of patients. J Clus Sci. 2017; 2. 1-11. DOI: 10.1007/s10876-0171267-0.

28. Zonaro E, Lampis S, Turner RJ, Qazi SJS, Vallini G. Biogenic selenium and tellurium nanoparticles synthesized by environmental microbial isolates efficaciously inhibit bacterial planktonic cultures and biofilms. Fronti Microbio. 2015; 6:1-11. DOI: 10.3389/fmicb.2015.00584.

29. Nejad SM, Shahidi Bonjar GH, Khatami M, Amini A, Aghighi S. In vitro and in vivo antifungal properties of silver nanoparticles against Rhizoctonia solani, a common agent of rice sheath blight disease. IET Nanobiotech. 2017; 11(3):236240. DOI: 10.1049/iet-nbt.2015.0121.

30. Soltanzadeh, M., Soltani Nejad, M. and Shahidi Bonjar, G. H. Application of Soil-borne Actinomycetes for Biological Control against Fusarium Wilt of Chickpea (Cicer arietinum) caused by Fusarium solani fsp pisi. J Phytopatho, 2016; 164: 967-978. DOI:10.1111/jph.12517.

31. Zilberberg L, Mitlin S, Shankar H, Asscher M. Buffer Layer Assisted Growth of Ag Nanoparticles in Titania Thin Films. $J$. Phys. Chem. C, 2015, 119(52):28979-28991. DOI: 10.1021/acs. jpcc.5b09621.

32. Philip D, Unni C, Aromal SA, Vidhu VK. Murraya Koenigii leafassisted rapid green synthesis of silver and gold nanoparticles. Spectro Act Par A: Mol Bior Spectro. 2011; 78(2):899-904. DOI: $10.1016 /$ j.saa.2010.12.060. 
33. Shankar SS, Ahmad A, Sastry M. Geranium leaf assisted biosynthesis of silver nanoparticles. Biotech Prog. 2003;19(6):1627-31 DOI: 10.1021/bp034070w.

34. Nejad MS, Khatami M, Bonjar GHS. Extracellular synthesis gold nanotriangles using biomass of Streptomyces microflavus. IET Nanobio. 2016; 10:33-38. DOI: 10.1049/iet-nbt.2015.0028.

35. Amaladhas TP, Sivagami S, Devi TA, Ananthi N, Velammal SP. Biogenic synthesis of silver nanoparticles by leaf extract of Cassia angustifolia. Advances in Natural Sciences: Nanosci Nanotech. 2012; 3(4):1-7. DOI: 10.1088/20436262/3/4/045006.

36. Chaturvedi V, Verma P. Fabrication of silver nanoparticles from leaf extract of Butea monosperma (Flame of Forest) and their inhibitory effect on bloom-forming cyanobacteria. Biores Biopro. 2015; 2(1):1-8. DOI: 10.1186/s40643-015-0048-6.

37. Jha AK, Prasad K. Green synthesis of silver nanoparticles using Cycas leaf. Int J Green Nanotech: Phy Chem. 2010; 1(2):P110-P7. DOI: 10.1080/19430871003684572.

38. Ravishankar Rai V, Jamuna Bai A. Nanoparticles and their potential application as antimicrobials. In: Mendez-Vilas A, editor. Science against microbial pathogens: communicating current research and technological advances. Format Res Cent; 2011; 5(4). 197-209. DOI: 10.4236/anp.2016.54022.

39. Min JS, Kim KS, Kim SW, Jung JH, Lamsal K, Kim SB, et al. Effects of colloidal silver nanoparticles on sclerotium-forming phytopathogenic fungi. T Pla Patho J. 2009; 25(4):376-80. DOI: 10.5423/PPJ.2009.25.4.376.

40. Malaikannan L, Marimuthu PN, Ramar M, Baskaralingam V. Antibacterial Effect of Green Synthesized Silver Nanoparticles Against Vibrio sp. Isolated from Broiler Chicken. J Adv Sci Res. 2012; 3(4):51-4. DOI: 10.5423/PPJ.2009.25.4.376.

41. Yallappa S, Manjanna J, Peethambar S, Rajeshwara A, Satyanarayan N. Green Synthesis of Silver Nanoparticles Using Acacia farnesiana (Sweet Acacia) Seed Extract Under Microwave Irradiation and Their Biological Assessment. J Clu Sci. 2013; 24(4):1081-92. DOI: 10.1007/s10876-013-0599-7.

42. Sondi I, Salopek-Sondi B. Silver nanoparticles as antimicrobial agent: a case study on E. coli as a model for Gram-negative bacteria. J Coll Inte Sci. 2004; 275(1):177-82. DOI:10.1016/j. jcis.2004.02.012.

43. Khatami M, Nejad MS, Salari S, Almani PGN. Plant-mediated green synthesis of silver nanoparticles using Trifolium resupinatum seed exudate and their antifungal efficacy on Neofusicocum parvum and Rhizoctonia solani. IET Nanobiotech. 2016; 10(4): 237-243. DOI: 10.1049/iet-nbt.2015.0078.

44. Agnihotri S, Mukherji S, Mukherji S. Size-controlled silver nanoparticles synthesized over the range 5-100 $\mathrm{nm}$ using the same protocol and their antibacterial efficacy. RSC $A d v$. 2014; 4(8):3974-83. DOI: 10.1039/C3RA44507K. 